\title{
MITO E VERDADE EM HESÍODO E PLATÃO
}

\author{
JAA TORRANO* \\ Faculdade de Filosofia, Letras e Ciências Humanas \\ da Universidade de São Paulo
}

RESUMO: O que significam os misteriosos versos 27-28 da Teogonia de Hesíodo? Nesses versos e na República de Platão, há uma mesma concepção de verdade, e assim essa concepção mítica de verdade e a teoria platônica do conhecimento têm uma estrutura semelhante. No discurso filosófico, essa estrutura se chama "dialética". Na República de Platão, a condenação da poesia hesiódica e homérica corresponde a exigências essenciais da dialética enquanto método filosófico.

PALAVRAS-CHAVE: Hesíodo; Platão; mito; verdade; dialética; a condenação da poesia.

O título "Mito e Verdade em Hesíodo e Platão" anuncia que se descrevem as concepções de linguagem e de verdade apresentadas por esses autores. Para esse fim, os textos de ambos são aproximados: o trecho da Teogonia de Hesíodo que fala da verdade das Musas ( $T$. v. 27-8) e se tornou um enigma, um desafio à inteligência hermenêutica dos helenistas, e o trecho do livro II da República de Platão, que fala de mito e de poesia, faz a crítica da poesia tradicional (épica, lírica e trágica) e é (mal) entendido como a condenação, sem mais, da poesia.

Começando por Hesíodo, não falaremos de um autor primeiro e de outro depois, mas ao comentarmos Hesíodo já falamos de Platão, pois falaremos de Hesíodo do ponto de vista do que entendemos ser a doutrina da verdade e a teoria do conhecimento platônicas, tal como ambas, doutrina e teoria, se inscrevem ínsitas nos versos de Hesíodo, e mais se explicitam com diversos desenvolvimentos, nos Diálogos de Platão, para quem desse modo as quer ler nos Diálogos.

Lendo-se o citado texto de Platão na perspectiva dos princípios que o organizam e que lhe dão coerência interna, não há nele mera condenação da poesia, que muitos ilustres helenistas acreditam ter encontrado, mas muito em- 
bora aí se encontre uma condenação (sob condições) da poesia, trata-se sobretudo da hermenêutica do mito, pois apresentam-se os princípios de uma hermenêutica do pensamento mítico como critérios para a compreensão dos versos de Hesíodo e dos outros poetas aí mencionados.

A Teogonia começa com uma invocação das Musas, que se desdobra num hino às Musas. O hino mostra o que são as Musas, e traz implícita descrição da ontologia mítica mediante vívida descrição das atividades habituais das Musas. O ser das Musas se descreve não só com a imagem da filiação paterna e materna (que implica a noção de Zeus e Memória e toda a teogonia), mas também com a noção mítica de Theós/Theoí, "Deus(es)". Não nos deixemos enganar pela comodidade da tradução de Theós por "Deus", pois na comodidade dessa tradução cremos que compreendemos perfeitamente o que significa em Hesíodo e o que significou para os gregos arcaicos essa noção mítica de Deuses (Theoł). Mas não compreendemos. Se não compreendemos, não pretendamos que sabemos, pois pretender que se sabe o que não se sabe é fonte de grandes equívocos, como mostram os textos de insignes helenistas. Não pretendemos que sabemos isso que não sabemos, mas queremos crer que já temos em vista a direção em que se deve pensar essa noção mítica de Deuses. Em que direção pensar essa noção mítica de Deuses é a indicação que queremos extrair dessas páginas do livro II da República, em que Platão fala a respeito dos týpoi perì theologías.

A Teogonia, no proêmio hino às Musas, conta a primeira epifania das Musas a Hesíodo. Os versos 22-34 descrevem a concepção hesiódica da linguagem, e descrevem sua experiência da linguagem e o encontro da verdade como interpelação de Musas:

Elas um dia a Hesíodo ensinaram belo canto quando pastoreava ovelhas ao pé do Hélicon divino.

Esta palavra primeiro disseram-me as Deusas Musas olimpíades, virgens de Zeus porta-égide:

"Pastores agrestes, vis infâmias e ventres só, sabemos muitas mentiras dizer símeis aos fatos e sabemos, se queremos, dar a ouvir revelações." Assim falaram as virgens do grande Zeus verídicas, por cetro deram-me um ramo, a um loureiro viçoso colhendo-o admirável, e inspiraram-me um canto divino para que eu glorie o futuro e o passado, 
impeliram-me a hinear o ser dos venturosos sempre vivos

e a elas primeiro e por último sempre cantar.

No verso 24, aparece a palavra mýthon. Nesse verso, a palavra mýthon é sinônimo de lógos, como é sinônimo de épos. Estas palavras mýthos, lógos e épos designam o ato de fala, e designam essa experiência da linguagem que se documenta nesses supra-citados versos de Hesíodo. Esses versos trazem implícito um conceito de mito como forma de linguagem. A riqueza desses versos nos permitiria encontrar neles todo um conceito de mito como o que Walter F. Otto expõe em seu livro Dionysus Myth and Cult. Nós encontraríamos também um conceito mais amplo de mito, que fala não só de uma experiência religiosa de mito e de culto grego arcaico, mas também um âmbito mais amplo da experiência da palavra, de que Platão participa, como herdeiro e intérprete de seu legado tradicional.

A palavra mýthon aqui, no verso 24, se refere às palavras com que as Musas mesmas se apresentam a Hesíodo, com que as Musas mesmas se definem a si mesmas e ao que é, perante elas, a realidade humana. Em três versos hexâmetros, as Musas se apresentam a Hesíodo: primeiro, definem a realidade humana como o interlocutor delas, a quem se dirigem e a quem interpelam, e depois se apresentam a si mesmas como senhoras cujo domínio é o das mentiras e das revelações. Nesses três hexâmetros, o mito se vê do ponto de vista do mito mesmo.

No primeiro dos três hexâmetros, define-se a realidade humana como kak'elégkhea, gastéres hoîon, que se pode traduzir "vis infâmias e ventres só". Gastéres, "ventres", é aqui uma metonímia da condição humana, na medida em que designam as duas funções nutritiva e reprodutiva como traços característicos da condição humana que a distinguem da vida divina. A função nutritiva é necessária à sobrevivência do indivíduo como a reprodutiva é necessária à sobrevivência da espécie, e a metonímia de "ventres" assinala ambas as necessidades como diferença específica que define a realidade humana. Ante a plenitude da vida divina, a realidade humana é determinada pela dupla necessidade de que "ventres" se faz emblema: nutrição para o indivíduo e reprodução para a espécie. Isentos dessa dupla necessidade, os Deuses são "imortais" (athánator) ou "sempre vivos" (aièn eónton). Contudo, as Musas se definem especificamente como senhoras cujo domínio é o das mentiras e das revelações. Nestes misteriosos versos em que elas falam de si mesmas, determinam-se a natureza da verdade e os quatros graus de presença da verdade entre os homens e os da participação dos homens na verdade: 


\section{Ídmen pseúdéa pollà légein etýmoisin homoîa, ídmen d', eut'ethélomen, alethéa gerýsasthai \\ Sabemos muitas mentiras dizer símeis aos fatos, \\ e sabemos, quando queremos, dar a ouvir revelações.}

Se aqui se determinam a natureza da verdade e os seus graus, compreendamo-la, pois, pelo (grau) que dela nos é acessível.

Digamos, então, ser presumível que nesses supra-citados versos se distinguem quatro graus da verdade e que essa distinção mais bem se deixe compreender pela leitura dialética que dela se faz. Essa leitura dialética só se torna possível no interior da teoria do conhecimento assinalada na famosa imagem da linha descrita no final do livro VI da República de Platão.

A imagem (eikón) da linha pede que imaginemos uma imagem de linha, designada eikón ("imagem"), e define o que é imagem (e assim, implicitamente, define também essa forma de linguagem e a experiência dela). $O$ que é imagem define-se relativamente a três outros graus de verdade e de conhecimento consideradas superiores à imagem em verdade e em clareza.

Nos versos 27-8 supra-citados, os quatro graus de verdade e de conhecimento são nomeados, na ordem em que as palavras aparecem: pseudéa, etýmoisin, homoîa e, superior a esses anteriores, alethéa. Não só se nomeiam os graus como se descreve a articulação entre esses quatro graus, e essa articulação é definida pela sintaxe da língua grega:

\section{Ídmen pseúdea pollà légein etýmoisin homôia}

Sabemos muitas mentiras dizer símeis aos fatos.

Esse verso grego pode-se considerar absolutamente intraduzível, neste sentido, a saber: nesse verso grego rebrilha uma ambigüidade sintática que traduz a ambigüidade característica desses graus de verdade aqui indicados.

A ambigüidade choca e desconcerta-nos e esse seu chocante e desconcertante impacto prepara-nos para pensar o que significa essa noção mítica de ser, nomeada Theaí, "Deusas" (v. 24).

Nenhuma tradução consegue reproduzir toda a amplitude desse ambíguo movimento em que as palavras das Musas se movem das muitas mentiras à realidade dos fatos. Tratemos de explicar o que a tradução não consegue reproduzir em outra língua. 
Ídmen é uma forma verbal antiga com valor perfectivo, indicando estado presente resultante da ação passada ("sabemos por termos visto"); no entanto, com um complemento no neutro plural (como, por exemplo, pseúdea pollà), o verbo ídmen indica um comportamento habitual ou um traço do caráter. Portanto, as primeiras palavras do verso ídmen pseúdea pollá, tomadas em seu isolamento inicial, poderiam soar em grego como "somos mentirosas muitas vezes".

Invocadas como fundamento da possibilibidade de acesso dos homens à verdade e assim invocadas como emblemática garantia da verdade do canto, a primeira coisa que as Deusas dizem de si mesmas é "somos mentirosas muitas vezes".

Só quando se ouve ou se lê a quarta palavra do verso, légein, percebe-se que o objeto de ídmen não é pseúdea, mas que pseúdea pollà completa o verbo légein, "dizer muitas mentiras". Nesse momento, as três palavras iniciais ídmen pseúdea polládeixam de soar como "somos mentirosas muitas vezes" e, integradas pela quarta palavra légein, em conjunto dizem: "sabemos dizer muitas mentiras".

Essa nova percepção altera o primeiro sentido descritivo de um modo de ser habitual ("somos mentirosas muitas vezes") para o descritivo de um conhecimento puramente intelectual: "sabemos dizer muitas mentiras".

Em seguida vem o dativo etýmoisin que diz sob que relação se devem pensar essas "muitas mentiras". Esta palavra etýmoisin aparece uma única vez na Teogonia, nesse verso 27, mas aparece algumas vezes na Odisséia e na Ilíada, e assim é possível observar que nesses textos ela significa a verdade cuja realidade o homem pode comprovar por si mesmo mediante verificação. Etýmoisin só se deixa traduzir por "fatos", se considerarmos que os "fatos", quando tomados na opulência de sua concretitude, contêm essa modalidade de verdade que etýmoisin descreve.

Etýmoisin significa "coisas reais", tais como são os "fatos". Na sintaxe desse verso, essa palavra completa o sentido do nome homoîa ("símeis"), que, em nobre posição de remate, qualifica pseúdea pollá ("muitas mentiras") e conclui o verso. São as duas posições importantes no verso hexâmetro a primeira e a última: homoîa tem essa posição final de destaque que lhe confere importância equivalente à da palavra ídmen em posição inicial na abertura do verso.

Homoîa significa "símeis". Na raiz de homoîa fala a unidade dos símeis como similitude. A palavra homoîa ("símeis") resgata essas pseúdea pollá ("muitas mentiras"), que as Musas sabem dizer, vinculando-as a etýmoisin, a "coisas reais", a "fatos". Esse resgate promovido pela assimilação de "muitas mentiras" a "coisas reais", eleva as "muitas mentiras" à dignidade de "símeis a coisas reais". Essas "muitas mentiras" são "símeis" a "coisas reais" e por essa similitude são equiparadas à reali- 
dade das "coisas reais" e dos "fatos", e assim contêm a verdade cuja realidade os homens podem verificar e comprovar por si mesmos. Nesta assimilação das "muitas mentiras" às "coisas reais", vige a força da similitude, que, no império da aparência, impõe ao pensamento mítico o esplendor da imagem e de sua concretitude.

No ambíguo movimento desse verso hexâmetro, o domínio das Musas se mostra nas aparentes "muitas mentiras" cuja aparência por fim se decide como similitude com a realidade das "coisas reais" e dos "fatos". A similitude é o modo de as aparências se reunirem, quando as aparentes imagens permanecem imagens e assim perduram na opulência de sua concretitude.

Nessas "muitas mentiras", então, vigora uma ambigüidade que lhes é essencial. A mentira é mentira no sentido da mera falsidade, em que a palavra pseúdea aparece no isolamento inicial do verso 27 , ou tem um outro sentido: o sentido de uma eficácia pela qual ela se vincula à verdade, e nessa ambígua unidade a mentira é símil a coisas reais.

Essa ambígua unidade, que resgata as mentiras vinculando-as às coisas reais, constitui um terceiro grau da verdade: o das aparências e da similitude, desde que se entenda a mera mentira (pseúdea) como o primeiro grau da verdade: o da privação da verdade.

Etýmoisin designa o segundo grau da verdade: o dessa verdade cuja realidade os homens podem verificar e comprovar por si mesmos.

A similitude dos símeis (homoîa), que vincula as mentiras das Musas às verdades que o homem mesmo pode comprovar, essa similitude se dá em face deste outro (quarto) grau de verdade: a suprema e plena presença das Musas e de suas "revelações". Alethéa, "revelações", é o nome que designa a natureza mesma das Musas e assim é o outro nome de Memória (Mnemosýne, mãe das Musas).

O nome alethéa se forma do prefixo de valor negativo a-e da mesma raiz que o nome Léthe. Alethéa significa o domínio da negação e da ausência de Léthe, "Obliviosa", filha da Noite imortal.

Léthe não é "esquecimento", "olvido", "oblívio", como um fenômeno psicológico, como um traço do comportamento humano.

Léthe, como uma forma divina do mundo, cujo nome mais bem se poderia traduzir "Obliviosa" ou "Latência", a filha da Noite, encobre e o assim encoberto passa despercebido aos homens.

Léthe, "Latência", filha da Noite tenebrosa, contrapõe-se de modo simétrico e especular a Mnemosýne, "Memória", filha de Terra e Céu, mãe das Musas, se uma e outra se consideram formas divinas e aspectos fundamentais do mundo. 
Nesse sentido, poder-se-ia traduzir a-lethéa por "re-velações", ou, indo mais longe na tentativa de reconstruir a palavra em seus elementos formadores, " $\mathrm{i}$ latências".

Um traço distintivo dessa concepção mítica de verdade como alethéa é que ela é um dom dos Deuses, um dom das Deusas Musas, como aliás tudo o mais, sob o ponto de vista da piedade arcaica. Sob essa perspectiva, todo fruto do esforço humano necessariamente é visto como um dom dos Deuses. Também o trigo é visto como um dom de Deméter. Não se pode esperar que o trigo frutifique nos campos, negligenciados esses severos trabalhos e disciplina agrícola, cujo ciclo sazonal Hesíodo descreve nos Trabalhos e Dias. Mas esse esforço disciplinado por severa observância e cuidado ininterrupto seria vão, se não fosse coroado com o favor divino e a Deusa não desse os seus dons em forma de espigas maduras. Assim também a verdade é um dom divino que coroa o esforço de quem busca o conhecimento da verdade como "revelações" de Musas.

Os supra-citados versos 27-8, palavras das Musas mesmas, abarcam todo o âmbito da verdade em seus quatro graus, que aí são distinguidos e definidos uns pelos outros, recíprocos no interior da ambígua unidade que lhes é inerente. Assim, essa concepção mítica de verdade como alethéa implica tanto a doutrina platônica da verdade quanto sua teoria do conhecimento, e nessa comunidade de formas de linguagem, a concepção hesiódica de verdade talvez se deixe compreender em seu sentido mais pleno.

Retornando aos pseúdea: tal como Léthe, "Latência", as "Mentiras" se inscrevem no catálogo dos filhos da Noite como forma divina e aspecto fundamental do mundo. Nesse sentido, pseúdea não é uma mentira que um homem diga porque decidiu dizê-la, mas antes as mentiras que se impõem ao homem porque este homem não pode ultrapassar limites próprios de sua condição e assim subtrair-se de sua dependência daquela forma divina do mundo.

Num primeiro passo, as "mentiras" (pseúdea) se contrapõem aos "fatos" (etýmoisin) e os excluem. Num segundo passo, os "fatos" se contrapõem a "mentiras" e as excluem. Num terceiro passo, verifica-se que "mentiras" e "fatos" em ambígua unidade estão unificados em face deste grau de verdade que os ultrapassa e que se mostra o passo das "revelações" (alethéa) das Musas mesmas.

Filhas de Zeus e Memória, e de certo modo contemporâneas dos acontecimentos, as Musas cantam o presente, o passado e o futuro, a totalidade do ser e do acontecer, e de certo modo tornam os seus ouvintes contemporâneos desses acontecimentos. Quem as ouve? 


\section{[...] Elas a Zeus pai}

hineando alegram o grande espírito no Olimpo

dizendo o presente, o futuro e o passado (v. 36-7);

Hineando alegram o espírito de Zeus no Olimpo (v. 51).

O proêmio da Teogonia assim descreve o canto jubiloso das Musas a Zeus no Olimpo e reiteradamente insiste na identidade entre o canto que se ouve no Olimpo e o que se canta na Teogonia. Essa reiteração intensifica e explicita a imagem e sua imitação, nesta seqüência. Primeiro, os versos iniciais do proêmio, descrevem-se as atividades habituais das Musas: o catálogo dos Deuses por elas hineados elenca os mesmos Deuses da Teogonia (vv. 11-22). Depois, os versos $36-$ 51 esclarecem que o conteúdo dos cantos divinos e eternos das Musas a Zeus no Olimpo é o conteúdo da Teogonia. Ainda, os versos 71-5, delineando mais, falam de Zeus e de suas vitórias, como conteúdo do canto das Musas:

\section{[...] Ele reina no céu}

tendo consigo o trovão e o raio flamante,

venceu no poder o pai Crono, e aos imortais

bem distribuiu e indicou cada honra;

isto as Musas cantavam tendo o palácio olímpio.

Nos versos finais do hino proêmio (vv. 104-15), que os estudiosos chamam de o "programa" da Teogonia, a súplica do cantor às Musas descreve o canto que esse lhes pede com o mesmo conteúdo do canto das Musas. A similitude une os cantos divinos das Musas no Olimpo, no ápice do Hélicon, ou no sopé do Hélicon e alhures, e o canto da Teogonia. O cantor desse canto constitui a imagem terrena, humana e finita do canto celeste, divino e eterno das Musas no Olimpo.

As Musas não só interpelam Hesíodo, como também lhe inspiram um canto para que ele cante o futuro e o passado, e lhe dão um cetro colhido de loureiro: insígnia, entre os gregos, da palavra autorizada e do poder de fazer-se ouvir. O aedo, o adivinho, o arauto e o orador, cada um em sua área de saber, portam o cetro como insígnia da palavra com poder de fazer-se cumprir por sua verdade. As Musas, ao interpelarem o cantor, impelem-no a construir com o canto o monumento que testemunhe a sublime presença das interpelantes tal 
como o cantor as contemplou na interpelação. Assim, sob o ponto de vista da piedade arcaica, a verdade dos cantos está em sua similitude com o canto divino das Musas, e a verdade do cantor reside em sua participação nas Deusas Musas.

Busquemos agora no texto de Platão como se formulam em termos filosóficos essa experiência tradicional da linguagem como mito e a concepção mítica de verdade como alethéa, "ilatências".

\section{Íthi, oûn, hósper en mýthoi mythologoûntes te khaì skholèn ágontes, lógoi paideúsomen toùs ándras (Rep. 376b-9) \\ Tal como quem narra mito e tem lazer, eduquemos com doutrina filosófica os homens.}

Nessa frase, mythologoûntes significa "narrar"; mýthoi, "palavra narrativa"; e lógoi, "doutrina filosófica", "enunciado filosófico". Reconhecida essa distinção de sentido nos vocábulos mýthoi e lógoi, propõe-se que a educação filosófica principie "pela palavra narrativa" (en mýthoi).

Num passo do Protágoras de Platão (320c-7), a personagem homônina, o célebre sofista, instado a demonstrar mais claramente que a virtude política se pode ensinar, pergunta: "a vós outros, jovens, eu, velho, devo demonstrar narrando mito ou faço um discurso filosófico?" (mýthon légon epideíxo è lógoi diexéltho.). Seus interloculores the respondem: "como queiras", e ele lhes diz: "parece-me mais gracioso narrar-lhes um mito" e conta o mito de Prometeu, atendendo a todas as exigências dos týpoi perì theologías. A especialização desses vocábulos mýthoi e lógoi para nomear formas diversas de usar a linguagem não impede que esses vocábulos fossem usados como permutáveis ou equivalentes, de modo a ter mýthoi onde se esperava ter lógoi e vice-versa. Essa permutabilidade ou equivalência entre ambos os vocábulos indica que ambos os usos da linguagem pertence ao âmbito de uma mesma comunidade de experiência da linguagem como mito e seus dons e antidoros.

Na República de Platão, a opção pelo mito como primeira forma de educação básica se justifica pela dificuldade de descobrir uma melhor que a usada há muito tempo: ginástica para o corpo e música para a alma. Por música entendase a poesia tradicional (épica, lírica e dramática), de que música strictu sensu não se dissocia; por música entendam-se os dons das Musas. O pretendido uso da poesia tradicional como forma de educação pede critérios que exigem reflexão e demandam estudo. Esses critérios implicam e indicam os princípios da hermenêutica do mito. Esses princípios são necessariamente dialéticos, não só 
porque agora se trata de compreender o mito e sua palavra narrativa do ponto de vista do discurso filosófico (lógoi diexéltho), mas sobretudo pela natureza mesma do que se há de compreender: essa concepção tradicional de verdade e de linguagem e o legado dessa experiência. A exposição desses critérios tem toda a aparência de uma severa condenação da poesia e é, em certo sentido.

$\mathrm{O}$ mito (e com ele a poesia tradicional) se define pela ambigüidade entre alethés e pseudés. Ainda que o discurso filosófico (lógos) também possa ser afetado por essa ambigüidade, neste passo da República examina-se especificamente a ambigüidade própria do mito, em que sentido é falso e em que sentido é verdadeiro, segundo deixa de atender ou atende às exigências dos týpoi perì theologías.

\section{- Lógon dè dittòn eîdos, tò mèn alethés, pseûdos d'héteros? - Naí. - Paideutéon d'en toîs pseudésin? - Ou mantháno, éphe, pôs légeis (Rep. 376e11) \\ - Há duas espécies de discursos, o verdadeiro e o falso? - Sim. - Há de se educar mediante o falso? - Não compreendo o que dizes, disse.}

Neste ponto, a perturbação no entendimento do interlocutor de Sócrates parece vir de ele subentender lógois na segunda pergunta de Sócrates, já que na pergunta anterior este fala de lógon. Sócrates desfaz a confusão substituindo a esperada palavra lógois pela equivalente mýthous:

- Ou mantháneis, ên d'egó, hóti prôton toîs paidíois mýthous légomen? Toûto dé pou hos tò hólon eipeîn pseûdos, éni dè kaì alethê(Rep. 377a4).

- Não compreendes, disse eu, que primeiro contamos mito às crianças? Esse mito é, por assim dizer, de um modo geral, mentira. Mas nele há também ilatências.

Reconhecida a aparente oposição entre o falso e o verdadeiro, reconhecem-se no interior do falso graus diversos de participação do falso no verdadeiro. Portanto, admitido que no mito haja extremos desde o de todo falso ao de todo verdadeiro, admitem-se graus intermediários entre um e outro extremos. Nesse ínterim, a distinção entre kalôs pseúdesthai, "mentir bem", e mè kalôs pseúdesthai, "não mentir bem", revela a ambigüidade do pseudés.

Esse mè kalôs pseúdesthai, "não mentir bem", que a helenista portuguesa M. H. R. Pereira traduz por "mentiras sem nobreza”, é o que se há de exprobrar e extirpar, condenados mito e poesia tradicional. Esse grau condenável de "men- 
tiras sem nobreza" corresponde à primeira compreensão do mito, ou seja, à primeira compreensão do que dizem as Musas a respeito de si mesmas: ídmen pseúdea pollá, "somos mentirosas muitas vezes".

Por outro lado, kalôs pseúdesthai, "mentir bem", as "mentiras com nobreza" ou "belas mentiras", como queira, são os primeiros recursos educativos no currículo dos guardiães e dos reis filósofos. A tradução de kalôs pséudesthai pode flutuar, mas seu sentido na teoria do conhecimento de Platão é rigorosamente claro. Pseúdesthai tanto se confunde com mè kalôs pseúdesthai, pela privação e ausência de "bem" em um e outro, quanto se distingue de kalôs pseúdesthai, pela presença de "bem" neste último. O sentido desse kalôs, "bem", é verdadeiramente compreensível através da imagem do sol, pois esse kalôs é uma forma de participação na "idéia do bem", he t'agathoû idéa.

A forma suprema e plena da verdade na teoria platônica do conhecimento se diz he t'agathoû idéa, "a idéia do bem", essa expressão introduz a imagem do sol e é por esta explicada (Rep. 505a).

A tradução de kalôs por "bem" está sujeita a equívoco tanto quanto a de Theós por "Deus(es)", e por isso precisa ser esclarecida de modo a ser possível precaver-se de equívoco. Para indicar a direção em que devemos pensar "a idéia do bem", Sócrates recorre à imagem e o recurso mesmo à imagem parece um alerta a que se precavenha do equívoco e do ridículo:

\section{[...] oneidizontes ge hóti ouk ismen tò agathón, légousin pálin hos eidósin (Rep. 505c) \\ [...] censurando-nos por não conhecermos o bem, falam em segui- da como se o conhecêssemos;}

[...] hos aû syniéton hemôn hóti légousin, epeidàn tò toû agathoû phthégxontai ónoma (Rep. 505c2)

[...] como se nós compreendêssemos o que eles querem dizer quando proferem o nome de 'bem'.

A imagem do sol indica e esclarece em que sentido pensar o kalôs desse kalôs pseúdesthai: como a eficácia das mentiras que participam da "idéia do bem" e portanto têm um grau de verdade, advindo dessa participação, pelo qual podem ser usadas de maneira eficaz na educação básica do currículo dos guardiães e dos reis filósofos. Os indícios dão a pensar kalôs e agathón no sentido da eficiên- 
cia de uma ação eficaz que tem uma realidade em si mesma como forma pela qual o ato em si mesmo tem eficácia e realidade. O "bem" desse "mentir bem" está em mentir com eficácia e assim produzir resultados benéficos na educação básica de guardiães e de reis filósofos.

Resumindo, há uma ambigüidade das Musas em Hesíodo como há uma ambigüidade da experiência da palavra em Platão. Como recurso de precaução ante essa ambigüidade, na República estabelecem-se princípios de hermenêutica do mito como critérios para inclusão ou exclusão de versos da poesia tradicional no currículo escolar.

Os poetas, quando mentem não belamente, não devem ter direito a voz, na educação do cidadão. E quando mentem não belamente? A exemplificação da maior das "mentiras sem nobreza" resulta já na condenação e exclusão completa de toda a Teogonia de Hesíodo como mentira sem absolutamente nada de bom nem de verdadeiro (Rep. 377e6-378a6). Victor Goldschmidt, em seu livro Questions Platoniciennes, dá duas indicações preciosas para o entendimento do sentido desse trecho da República em seu caráter dialético. $\mathrm{O}$ verdadeiro sentido dessa condenação, do ponto de vista da coerência interna do texto de Platão, é dado pela dialética. Para essa leitura dialética, contribuem essas indicações de Goldschmidt.

A primeira é a explicação do valor semântico de theologías na expressão týpoi perì theologías. A história dessa palavra registra uma duplicidade de sentido, bem antes que este sentido que Aristóteles lhe deu de próte philosophía, "a parte mais nobre da filosofia teorética, designada mais tarde como metafísica" (Goldschmidt, 1970, p. 142. Metaf. E, 1, 1026 19; k, 7, 1064 a 33-b 3) sobrepujasse este outro sentido com que se designavam Hesíodo e Ferecides, e distinguiamse de filósofos contemporâneos de Aristóteles (Goldschmidt, 1970, p. 141. Metaf. A, 3, 983b27; N, 4, 1091a34). Em sua primeira e única aparição na República (379a5) theologías designa essa parte da mitologia que trata dos Deuses mitológicos, por distinção da parte que trata dos Daímones, da parte que trata dos Heróis e dos (que estão) no (palácio de) Hades. Týpoi perì theologías, portanto, são marcas a serem observadas quando se trata de Deuses, por certo os Deuses de Hesíodo.

As marcas e as leis, quando se trata de Deuses, assim se formulam: 1) agathòs hóge Theòs tôi ónti, "o Deus é essencialmente bom”, e mè pánton aition tòn Theòn allà tôn agathôn, "o Deus não é causa de todas as coisas, mas só das coisas boas"; e 2) haploûn te eînai kaì pánton hékista tês heautoû idéas ekbaínein, "é simples e o menos capaz de sair de sua própria forma” (Rep. 379b; 380c6; 380d5). 
A segunda indicação de Victor Goldschmidt, preciosa para o entendimento desse trecho da República em seu caráter dialético, está no estudo intitulado "A linha da República e a classificação das ciências" e assinala que a ordem dos temas nesse diálogo reflete a da construção da imagem da linha, pois os fundadores e legisladores da cidade logo de início deparam com a necessidade de elaborar e discutir o programa educacional e examinam os versos do ponto de vista do grau de conhecimento próprio aos jovens, a saber, o da imagem, e à medida que os legisladores estabelecem as etapas do currículo, o temário de cada etapa reflete os graus de conhecimento descritos nos sucessivos segmentos da construção da imagem da linha (Goldschmidt, 1970, p. 203).

Na imagem da linha (Rep. 509d-514a), a teoria do conhecimento de Platão é apresentada sub specie imaginis: uma imagem rica e complexa que incorpora todos os elementos que já haviam entrado na contrução da imagem construída imediatamente antes, a do sol, e cujos elementos entram na contrução da imediatamente posterior, a da caverna. Essas três imagens, a do sol, a da linha e a da caverna, têm em comum a designação eikón, que a cada uma delas define, e o intento precípuo, que lhes orienta a construção, de mostrar a determinação recíproca dos quatro graus do conhecimento. Um desses quatro graus, o menos verdadeiro e o mais obscuro, é o da imagem, eikón. Os outros graus, os de dóxa, diánoia e nóesis, desse se distinguem, em escala ascendente, por uma cada vez maior participação em verdade e em clareza. Os graus do conhecimento são necessariamente graus de participação na verdade e no ser, dado que um dos traços característicos dessa concepção mítica e platônica da verdade é o nexo necessário entre conhecimento, verdade e ser.

Quando se trata dos poetas e de como os poetas tratam dos Deuses mitológicos, necessariamente se trata das possibilidades e impossibilidades inerentes ao conhecimento e à natureza da imagem, e determinadas elas também pela ambigüidade entre verdadeiro e falso própria à imagem.

Nessa área de ambigüidade entre o falso e o verdadeiro, a imagem mostra o seu aspecto falso, mas também o seu aspecto verdadeiro e ainda a unidade de um e outro aspectos: falsa quando imita uma imagem sensível, verdadeira quando imita a forma inteligível.

A condenação da poesia reside no lado sinistro pelo qual a imagem se mostra como imagem da imagem. O louvor da poesia reside no lado destro pelo qual a imagem sensível imita a forma inteligível. $\mathrm{O}$ resgate da poesia e a passagem da condenação ao louvor ou o impasse da condenação residem na similitude que une a imagem sensível e a forma inteligível. 
A condenação da poesia é a explicitação de uma intrínseca exigência do método dialético, da mesma forma que a condenação da retórica no Górgias e seu resgate no Fedro, e ainda nesse mesmo diálogo, a condenação e o elogio do amor, e a condenação da escrita e seu equívoco resgate. Entretanto, nesse passo do livro II da República, o que caracteriza a condenação da poesia como fundada no lado esquerdo da imagem, sendo, portanto, possível o louvor da poesia fundado no lado direito da imagem? Ao que parece, são quatro os indícios do caráter dialético da condenação da poesia.

O primeiro indício de que a poesia está sendo considerada sob o aspecto da imagem é sua associação à ginástica. Na primeira etapa do programa educacional, a música trabalha com a imagem, objeto do primeiro grau do conhecimento, assim como na segunda etapa do programa a ginástica trabalha com o de que há imagem, a saber, o corpo, objeto do segundo grau do conhecimento.

O segundo indício é a definição mesma de mito como mentiras nas quais há também verdades. Definir assim o mito por essa ambigüidade essencial é mostrá-lo sob o ponto de vista da imagem.

O terceiro indício é a abordagem do mito como contado a "insensatos e jovens", a "crianças" (áphronas te kaì néous, Rep.378a; tà paidía, 378d), aos quais o mito só é acessível como imagem. Áphron, amathés e elithios se associam e se aparentam a anóetos, e têm em comum o valor semântico de "sem-intelecção". Nóesis, "intelecção", é essa afecção da alma correspondente à percepção intelectual das formas inteligíveis. Eíde, idéai, nóesis pertencem ao quarto supremo e pleno grau do conhecimento. Como os jovens ainda não têm, e os insensatos não mais, essa modalidade de inteligência, a nóesis, só é possível contar-lhes qualquer coisa que entendam, se lhes é contado sob o aspecto da imagem e de o de que há imagem.

O quarto indício é a citação e uso de versos que os extrai de seu contexto e que os toma em seu isolamento, atomizando-os. Essa atomização, esse isolamento, essa multiplicação e essa fragmentação indefinível, sem nenhuma sintaxe senão a da multiplicidade fragmentada, caracterizam o âmbito da imagem. Na República, os versos são citados e usados como imagens não integradas na unificação da marcha dialética que as vincula à verdade das formas inteligíveis.

Resumindo, vimos o que é a condenação da poesia e por que essa condenação se inscreve na marcha dialética como um passo necessário que pressupõe e prepara o louvor da poesia, que se anuncia no livro X da República.

A passagem da condenação ao louvor é decidida na escolha entre o lado sinistro e o destro da imagem: no lado sinistro, a imagem imita uma imagem; no lado destro, a imagem sensível participa da forma das formas inteligíveis. 
Quando se trata de Deuses (perì theologías), na decisão da escolha entre um e outro lado, para que se saiba de que lado se vê a imagem, valem como critério os týpoi perí theologías, assim formulados: 1) "o Deus é essencialmente bom" e "não é causa de todas as coisas, mas só das coisas boas"; e 2) "é simples e o menos capaz de sair de sua própria forma" (Rép. 379b; 380c6; 380d5). Como essas marcas (týpoi) demarcam um e outro lados da imagem?

$\mathrm{Na}$ formulação de que todo Deus é bom e causa somente de bens, devemse entender "bom" (agathós) e "bens" (agathôn) no mesmo sentido em que entendemos o "bem" de "mentir bem" (kalôs pseúsdesthar) e "o bem" de "a idéia do bem" (he t'agathoû idéa). Mas o que é "o bem"? Para responder a essa pergunta, no livro VI da República, Sócrates recorre à imagem e descreve a imagem do sol. Ao explicá-la, diz que assim como o sol dá nutrição, sustento e visibilidade às coisas visíveis, "a idéia do bem" dá ser, verdade e cognoscibilidade às formas inteligíveis, ou seja, as formas inteligíveis somente são verdadeiras e inteligíveis à medida que participam da "idéia do bem", a forma das formas. Nessa imagem, o sentido em que pensar "o bem" é assinalado por três distinções: 1) entre os visíveis e a causa deles, 2) entre os sensíveis (i.e. visíveis) e os inteligíveis, e 3) entre os inteligíveis e a causa deles; e por três comparações: os inteligíveis são superiores aos sensíveis assim como "a idéia do bem" é superior aos inteligíveis (Rep. 508c509b10).

Na primeira "marca" (týpoi), agathós como epíteto de Theós associa essa noção mítica de Theós à noção filosófica de t'agathón e assim estabelece uma correspondência entre as palavras fundamentais no sistema de imagens e de noções próprio do pensamento mítico documentado na poesia tradicional, de um lado, e, de outro lado, os termos próprios do discurso filosófico. Essa indicação de pensar a noção mítica de Theós no sentido da noção filosófica de eîdos/idéa é reiterada por outros indícios, em outros diálogos. No Fédon, por exemplo, atribuem-se às formas inteligíveis os epítetos que tradicionalmente o pensamento mítico grego atribuiu aos Deuses e assim se revela uma estrutura comum a ambas as noções: mítica e filosófica.

Poderíamos explicar idéa e Theós como "formas fundamentais do mundo" ou como "aspectos divinos do mundo", "formas em que se mostram os fundamentos de todas as possibilidades que se abrem para os homens mortais e especialmente a de sermos homens mortais". Não poderíamos desdenhar de traduzir t’agathón por "o bem", idéa por "idéia", e Theós por "Deus(es)", ainda que essas traduções sejam sujeitas a equívoco. A palavra "Deus(es)" tem para nós a vantagem inexcedível de ainda ecoar nela a sacralidade que ela teve um dia. 
Nos Diálogos de Platão, quando se trata de mitos, sejam eles os já documentados na poesia tradicional, sejam outros, o discurso dos Deuses observa rigorosamente as marcas e as leis formuladas como týpoi perì theologías. Alguns helenistas e platonistas crêem que Sócrates, quando fala de Deuses, está tratando o seu interlocutor com ironia, porque trata de Deuses como de dóxa, "opinião", mas nesse caso, a ironia estaria menos na fala de Sócrates que na ambigüidade comum à opinião e à imagem como graus de conhecimento.

\section{Nota}

* Professor Doutor de Língua e Literatura Grega do Curso de Graduação e do Programa de Pós-Graduação em Letras Clássicas da FFLCH-USP.

\section{REFERÊNCIAS BiBLIOGRÁFICAS}

GOLDSCHMIDT, V. Questions Platoniciennes. Paris: Vrin, 1970.

HESÍODO. Teogonia. Tradução de Jaa Torrano. São Paulo: Iluminuras, 1991

OTTO, Walter F. Dionysus Myth and Cult. Tradução de R. B. Palmer. Bloomington: Indiana University, 1965.

PLATÃO. República. Tradução de M. H. da Rocha Pereira. Lisboa: Fundação Calouste Gulbenkian, 1983.

PLATO. Opera. Edicted by J. Burnet. Oxford: Clarendon, 1900-7. 5 v.

TORRANO, Jaa. Myth and truth in Hesiod and Plato.

ABSTRACT: In the Hesiod's Theogony, what do the mysterious verses 27-28 mean? In these verses and in Plato's Republic, there is the same conception of the truth, and so this mythic conception of truth and the platonic theory of knowledge have a similar structure. In the philosophical speech, this structure is called "dialectics". In Plato's Republic, the hesiodic and homeric poetry condemnation meets with essential requirements of the dialectics as a philosophical method.

KEYWORDS: Hesiod; Plato; myth; truth; dialectics; the condemnation of the poetry. 